REGARDS

SUR LEECONOMIE ALLEMANDE

BULLETIN ECONOMIQUE DU CRAC

\section{Regards sur l'économie allemande}

Bulletin économique du CIRAC

$93 \mid 2009$

Varia

\title{
CEuvres : les Allemands sont des donateurs assidus
}

\section{Solène Hazouard}

\section{CpenEdition}

Journals

Édition électronique

URL : http://journals.openedition.org/rea/3916

DOI : 10.4000/rea.3916

ISBN : 978-2-8218-0882-9

ISSN : 1965-0787

Éditeur

CIRAC

Édition imprimée

Date de publication : 1 octobre 2009

Pagination : 36

ISSN : 1156-8992

Référence électronique

Solène Hazouard, « Euvres : les Allemands sont des donateurs assidus », Regards sur l'économie allemande [En ligne], 93 | octobre 2009, mis en ligne le 01 octobre 2011, consulté le 15 septembre 2020. URL : http://journals.openedition.org/rea/3916

Ce document a été généré automatiquement le 15 septembre 2020

(C) CIRAC 


\title{
Euvres : les Allemands sont des donateurs assidus
}

\author{
Solène Hazouard
}

\section{Des dons en hausse depuis le milieu des années 1990}

1 Près d'un citoyen allemand sur deux soutient aussi bien les associations culturelles et sportives communales que les organisations caritatives internationales. La somme versée à cet effet par les plus de 14 ans a considérablement augmenté depuis le milieu des années 1990, passant de $78 €$ en 1995 à $102 €$ en moyenne en 2008, avec un pic à $119 €$ en 2006, selon la dernière édition de l'enquête sur les donations (Spendenmonitor) de l'Institut de démoscopie Emnid. Le montant total des dépenses d'ordre social, culturel ou caritatif s'élevait en 2008 à près de 3 milliards $€$, révélant que la crise n'a guère réduit la générosité des Allemands (en 2007, leurs dons se montaient à $107 €$ par personne). En moyenne, ce sont près de $40 \%$ des adolescents et adultes qui mettent ainsi chaque année la main au porte-monnaie, avec bien sûr une hausse visible en cas de catastrophe relayée par les médias, comme lors de la crue de l'Elbe en août 2002 ou du tsunami ravageant le Sud-Est de l'Asie en décembre 2004 (voir REA 70/05).

\section{Pas de profil-type du donateur, mais des contours se dessinent}

Bien qu'il n'existe pas de profil-type du donateur outre-Rhin, on constate que les femmes sont plus enclines à donner, tout comme les personnes d'un certain âge. Eu égard à la catégorie professionnelle, ce sont les fonctionnaires et les travailleurs indépendants qui se montrent les plus généreux. Il n'est pas surprenant de constater que les ménages percevant un revenu mensuel de plus de $4000 €$ sont particulièrement prodigues : $81 \%$ de ceux-ci donnent régulièrement. L'appartenance religieuse constitue un autre facteur car si un citoyen sur trois sans confession compte parmi les donateurs, 
ils sont deux sur trois au sein de la communauté chrétienne, voire $80 \%$ parmi les plus croyants.

\section{Augmentation du nombre de fondations}

Dernière tendance de fond: l'engagement social croissant de personnes fortunées et d'entreprises via la constitution de fondations. Le nombre de fondations nouvellement créées n'a cessé de croître, passant ainsi de 181 en 1990 au chiffre record de 1134 en 2007. Selon la Fédération allemande des fondations (Bundesverband Deutscher Stiftungen), l'Allemagne comptait au début de l'année 2009 non moins de 16406 fondations de droit civil pour un patrimoine total de plus de 100 milliards $€$ : un cinquième d'entre elles disposait de moins de $50000 €$, près de la moitié détenait un capital situé entre 50000 et $500000 €$ et seulement près d'un cinquième avait plus de 2,5 millions $€$ à son actif. Mais la crise ne reste pas sans effet: les cinq plus grandes fondations allemandes (les fondations Robert Bosch, Dietmar Hopp GmbH, Volkswagen, la fondation du Land de Bade-Wurtemberg et la Deutsche Bundesstiftung Umwelt) ont vu leur patrimoine chuter de $7 \%$ en un an pour s'établir désormais à près de 15 milliards $€$. (SH)

INDEX

Mots-clés : association, don, financement, fondation, groupe social, société 